\title{
Causes of gastrointestinal colic at an equine referral hospital in South Africa (1998-2007)
}

\author{
A Voigt ${ }^{a}, M^{2}$ S Saulez ${ }^{a^{*}}, C$ M Donnellan ${ }^{a}$ and B Gummow ${ }^{b}$
}

\begin{abstract}
The most common causes of gastrointestinal colic at an equine referral hospital in South Africa were determined following retrieval of the medical records of horses admitted during a 10-year study period. The study included 935 horses of which $28 \%$ were admitted after hours. Most horses were Thoroughbreds (54\%), male (57\%), with a mean age of 8.2 years and originated from the Gauteng Province $(81 \%)$. Heart rate $(98 \%)$, mucous membrane colour $(95 \%)$ and auscultation of the abdomen $(91 \%)$ were the clinical data commonly obtained at admission. Packed cell volume, total serum protein and white cell count were recorded in $78 \%, 75 \%$ and $44 \%$ of horses respectively. Transrectal palpation (93\%), nasogastric intubation $(84 \%)$, intravenous catheterisation $(74 \%)$ and abdominocentesis $(53 \%)$ were the most frequently performed procedures. Medical intervention was performed in 558 horses $(60 \%)$. The common causes of medical colic were impactions (39\%), tympany $(7 \%)$ and displacement of the large colon (6\%). An exploratory laparotomy was performed in 331 horses $(36 \%)$. The common causes of surgical colic were displacement $(29 \%)$, impaction (22\%) and small intestinal strangulating lesions (18\%). Death occurred in $3 \%$ of horses, while euthanasia before medical intervention was performed in $4 \%$. Overall, medical intervention was successful in $93 \%$ of horses and $67 \%$ in horses managed surgically. In conclusion, $55 \%$ of all the equine admissions responded to medical intervention and the recovery rate for horses receiving both medical and surgical intervention was comparable to that reported in other studies.
\end{abstract}

Keywords: abdominal pain, horse, medical and surgical intervention, survival.

Voigt A, Saulez M N, Donnellan C M, Gummow B Causes of gastrointestinal colic at an equine referral hospital in South Africa (1998-2007). Journal of the South African Veterinary Association (2009) 80(3): 192-198 (En.). Section of Equine Medicine, Department of Companion Animal Clinical Studies, Faculty of Veterinary Science, University of Pretoria, Private Bag X04, Onderstepoort, 0110 South Africa.

\section{INTRODUCTION}

Equine veterinarians frequently treat horses with colic caused by visceral abdominal pain or non-gastrointestinal causes. Visceral abdominal pain is more commonly treated and may be caused by intestinal distension due to fluid, gas or ingesta, tension on the mesentery, ischaemia or infarction, ulceration of the mucosa, or peritoneal pain ${ }^{36}$.

Studies have examined the incidence of colic events ${ }^{1,38,40}$ in general and in specific breeds ${ }^{19,33,34}$. Some focused on specific causes such as caecal impaction ${ }^{30}$, peritonitis $^{17,23}$, large colon impaction ${ }^{9}$, small colon impaction $^{35}$, enterolithiasis ${ }^{8,16}$, idiopathic muscular hypertrophy ${ }^{6}$, sand colic ${ }^{32}$ and pedunculated lipoma ${ }^{11,15}$. The risk factors ${ }^{4,7,20,22,39}$ for, outcomes $e^{2,14,24}$ of, prognostication $^{21,31,37,41}$ of and the economic $\operatorname{cost}^{12}$ involving colic episodes have a Section of Equine Medicine, Department of Companion Animal Clinical Studies, Faculty of Veterinary Science, University of Pretoria, Private Bag X04, Onderstepoort, 0110 South Africa.

bschool of Veterinary and Biomedical Science, Faculty of Medicine, Health and Molecular Science, James Cook University, Townsville, Australia.

*Author for correspondence.

E-mail: montague.saulez@up.ac.za

Received: March 2009. Accepted: August 2009. also been reported in countries other than South Africa. To the authors' knowledge, no previous studies have been conducted to establish the causes of gastrointestinal colic in horses in South Africa.

The purpose of this study was to determine the most common causes and the outcome of gastrointestinal colic in horses admitted to the Equine Clinic of the Onderstepoort Veterinary Academic Hospital (OVAH) over a 10-year period.

\section{MATERIALS AND METHODS}

\section{Case selection}

The medical records of 1201 horses that were admitted to the Equine Clinic of the OVAH between 1 January 1998 and 31 December 2007 for gastrointestinal colic were reviewed. For the purpose of this study, colic due to reproductive, urinary, musculoskeletal and respiratory disease were excluded. The diagnosis of colic was confirmed by physical examination, rectal palpation, transabdominal ultrasound, abdominocentesis, nasogastric intubation, exploratory laparotomy or necropsy.

\section{Data management}

Data were evaluated and divided into 8 categories: study population information, signalment and history, pre-admission data, clinical data at admission, clinicopathological data, procedures performed, treatment data and survival to discharge information. Study information recorded time of admission, the number of repeat admissions due to colic and the total number of admissions per month and year. Signalment and history included the age, breed, sex, weight and geographic location of affected horses. Pre-admission data recorded the duration of colic signs and treatment administered before referral.

Clinical data recorded at admission included cardiovascular parameters, temperature, presence of abdominal distension, mucous membrane colour, capillary refill time and borborygmi. The degree of pain on presentation was defined as no pain if the horse showed no colic signs, depressed if the horse was lethargic, mild if the horse was intermittently pawing and looking at the flank, marked if the horse was persistently pawing and rolling occasionally and severe if the horse was persistently rolling and thrashing and the pain was uncontrollable despite using analgesics.

Clinicopathological data recorded included a complete blood count, serum biochemistry, blood gas analysis, urine and faecal analysis as well as abdominal fluid cytology. Clinical procedures recorded included nasogastric intubation, rectal palpation, caecal trocharisation, intravenous catheterisation, gastroscopy, ultrasonography and radiography. Treatment data included: pre-treatment euthanasia/death at admission, medical treatment and surgical exploration.

Survival to discharge data recorded whether horses survived the medical or surgical intervention, the number of days hospitalised and the total hospitalisation cost per day per case (South African rand, ZAR).

\section{Statistical analyses}

Statistical data were stored in Microsoft Excel 2003 and analysed using Microsoft Excel 2003 and NCSS 2004 (NCSS and PASS number cruncher statistical sys- 
tems, Kaysville, Utah 2001; www.ncss. com). Descriptive statistics were calculated for each measured parameter and the data tested for normality. Parameter data that were not normally distributed were analysed as nonparametric data. Continuous data that were normally distributed are reported as mean \pm standard deviation (SD) and continuous data that were not normally distributed are reported as median and range.

\section{RESULTS}

\section{Study population}

Of the 1201 medical records, $159(13 \%)$ were unavailable and $107(9 \%)$ were from horses admitted more than once. Therefore, 935 horses $(78 \%)$ were included in this study of which $72 \%$ were admitted during normal hours and $28 \%$ after hours. Medical and surgical intervention was performed on 411/238 horses respectively during normal hours and 147/93 horses respectively after hours. The pretreatment euthanasia/death at admission category included 26 horses admitted during normal hours and 20 horses after hours. The total admissions for January to December during the 10 years were calculated and a steady admission rate between $6.52 \%$ and $11.55 \%$ was obtained. The proportion of horses admitted during the 6 hottest months of the year, October to March, represented $51 \%(n=476)$ and those admitted during the remainder of the year represented $49 \%(n=459)$ of the study population.

\section{Signalment and history}

The age of horses admitted ranged from 3 weeks to 28 years (mean \pm SD, $8.2 \pm$ 5.1 years) with the highest admission rate for horses between the ages 5-10 years $(36.4 \%)$, the majority being male $(57 \%)$ and most originating in Gauteng Province $(81 \%)$. Breeds most represented were Thoroughbreds (54\%), Warmbloods $(11 \%)$ and Arabians (9\%) with American-saddlebred horses, Friesian horses and Welsh ponies comprising $<6 \%$ each.

\section{Pre-admission data}

The median duration of pre-admission colic symptoms recorded in $53 \%$ of horses was 11 hours (range, 0.5-168 hours). Of these horses, $61 \%$ were admitted within 12 hours after the onset of colic symptoms. The median duration of colic signs before admission for the surgical, medical and pre-treatment euthanasia/ death at admission category was 10, 12 and 14 hours, respectively. Pre-admission treatment was administered to $73 \%$ of the horses and included anti-inflammatory and other analgesic drugs (78\%), oral and

Table 1: Clinicopathological data commonly obtained during admission of horses with gastrointestinal colic at the Equine Clinic of the OVAH (1998-2007). Data for medical, surgical and pre-treatment euthanasia/death cases which are different to the descriptive statistic are given separately.

\begin{tabular}{|c|c|c|c|}
\hline Parameter & $\begin{array}{c}\text { Number of } \\
\text { horses }\end{array}$ & $\begin{array}{l}\text { Mean } \pm \text { SD/ } \\
\text { Median }\end{array}$ & Range \\
\hline $\begin{array}{l}\text { Packed cell volume (\%) } \\
\text { - Medical } \\
\text { - Surgical } \\
\text { - Pre-treatment }\end{array}$ & 729 & $\begin{array}{l}40 \pm 9 \\
39 \pm 8 \\
41 \pm 10 \\
46 \pm 13\end{array}$ & $\begin{array}{l}14-85 \\
14-71 \\
21-85 \\
25-75\end{array}$ \\
\hline Total serum protein $(\mathrm{g} / \ell)$ & 705 & $68 \pm 9$ & $30-110$ \\
\hline Albumin $(g / \ell)$ & 225 & $32 \pm 5$ & $15.7-46.3$ \\
\hline Globulin $(g / \ell)$ & 223 & $35 \pm 8$ & $13.3-46.3$ \\
\hline White cell count (cells/l) & 407 & $9.6 \times 10^{9}$ & $0.9-34.4 \times 10^{9}$ \\
\hline Mature neutrophils (cells/l) & 404 & $6.5 \times 10^{9}$ & $0-23.4 \times 10^{9}$ \\
\hline $\begin{array}{l}\text { Immature neutrophils (cells/l) } \\
\text { - Medical } \\
\text { - Surgical } \\
\text { - Pre-treatment }\end{array}$ & 296 & $\begin{array}{l}0.32 \times 10^{9} \\
0.20 \times 10^{9} \\
0.55 \times 10^{9} \\
1.76 \times 10^{9}\end{array}$ & $\begin{array}{l}0-24.7 \times 10^{9} \\
0-24.7 \times 10^{9} \\
0-8.95 \times 10^{9} \\
0-4.5 \times 10^{9}\end{array}$ \\
\hline Fibrinogen $(\mathrm{g} / \ell)$ & 87 & $4.03 \pm 1.78$ & $1-9$ \\
\hline $\begin{array}{l}\text { Abdominal fluid nucleated } \\
\text { cell count (cells/l) } \\
\text { - Medical } \\
\text { - Surgical } \\
\text { - Pre-treatment }\end{array}$ & 138 & $\begin{array}{l}1.7 \times 10^{9} \\
1.36 \times 10^{9} \\
1.9 \times 10^{9} \\
2.55 \times 10^{9}\end{array}$ & $\begin{array}{l}0.011-255.6 \times 10^{9} \\
0.011-255.6 \times 10^{9} \\
0.012-164.8 \times 10^{9} \\
0.5-158 \times 10^{9}\end{array}$ \\
\hline $\begin{array}{l}\text { Abdominal fluid total protein }(\mathrm{g} / \mathrm{l}) \\
\text { - Medical } \\
\text { - Surgical } \\
\text { - Pre-treatment }\end{array}$ & 306 & $\begin{array}{l}24 \pm 13 \\
23 \pm 14 \\
25 \pm 13 \\
25 \pm 12\end{array}$ & $\begin{array}{l}4-80 \\
4-70 \\
4-80 \\
5-50\end{array}$ \\
\hline
\end{tabular}

intravenous fluids (36\%), sedation (30\%) and antibiotics $(9 \%)$.

\section{Clinical data at admission}

Heart rate was recorded in 914 horses (98\%); median heart rate was 48 beats/ minute (range, 20-180 beats/min). The median heart rate of the horses in the medical, surgical and pre-treatment euthanasia/death at admission category was 44 beats/min (range, 20-150 beats/min), 52 beats/min (range, 25-180 beats/min) and 70 beats/min (range, 39-140 beats/ min), respectively.

Rectal temperature, respiration rate and capillary refill time were recorded in 840 $(90 \%), 809(87 \%)$ and 729 horses (78 \%). Rectal temperature ranged from $33.7^{\circ} \mathrm{C}$ to $43^{\circ} \mathrm{C}$ (mean $\left.\pm \mathrm{SD}, 38^{\circ} \mathrm{C} \pm 1^{\circ} \mathrm{C}\right)$, median respiration rate was 20 breaths/minute (range, 8-110 breaths/min) and median capillary refill time was 2 seconds (range, 1-4.5 seconds). No statistical difference was detected for temperature, respiration rate and capillary refill time between the medical, surgical and pre-treatment euthanasia/death cases.

Mucous membrane colour was recorded in 885 horses (95\%), with cyanosis occurring more frequently in the pre-treatment euthanasia/death at admission category (23\%), while congestion was recorded more frequently in horses requiring surgery $(24 \%)$. Abdominal distension was recorded in 787 horses $(84 \%)$ and was present in $42 \%$. Borborygmi were recorded in 849 horses (91\%) of which $63 \%$ had decreased borborygmi and $7 \%$ had no borborygmi.

Pain character and severity were recorded in 798 horses (85 \%). Twenty-two per cent of horses were alert and showed no pain, while depression, mild pain, marked pain and severe pain were recorded in $12,44,13$ and $9 \%$, respectively. The pre-treatment euthanasia/death at admission category had the highest recorded percentage of marked and severe pain $(48 \%)$.

\section{Clinicopathological data}

At admission, packed cell volume, total serum protein and white cell count were recorded in $729(78 \%), 705(75 \%)$ and 407 horses $(44 \%)$, respectively (Table 1 ). The packed cell volume mean \pm SD was $40 \% \pm 9 \%$ (range, $14 \%-85 \%$ ) and total serum protein was $68 \mathrm{~g} / \mathrm{l} \pm 9 \mathrm{~g} / \mathrm{l}$ (range, $30-110 \mathrm{~g} / l)$. The white cell count ranged from 0.9 to $34.4 \times 10^{9}$ cells $/ \ell$ (median $9.6 \times$ $10^{9}$ cells/ $/$ ). A serum biochemical analysis was performed in less than $24 \%$ of the horses. Urine analysis was recorded in $45(5 \%)$ and faecal analysis in 152 horses (16\%). Of all the admissions, abdominocentesis was performed in 493 cases $(53 \%)$ and most commonly in the pre-treatment euthanasia/death at admission category 
(76\%). Abdominal fluid appearance $(68 \%)$, total protein $(62 \%)$ and nucleated cell count $(28 \%)$ was most frequently recorded. Table 1 contains the most commonly reported clinicopathological data.

\section{Procedures performed}

The most common procedures performed are illustrated in Fig. 1. Ninetythree per cent of horses were examined transrectally and the results were classified as unremarkable (19\%), distension (42\%), impaction (36\%), displacement $(18 \%)$ or gastrointestinal rupture $(1 \%)$.

\section{Treatment}

\section{Pre-treatment euthanasia/death at admission category.}

Of the 935 horses reviewed in the study, 46 horses $(5 \%)$ received no treatment as 40 horses were euthanased due to a poor prognosis while 6 horses died following clinical examination. A diagnosis was made at necropsy on 31 horses but was not included in the study results as no treatment was performed (Fig. 2).

\section{Medical treatment.}

The gastrointestinal lesions that were treated medically are presented in Fig. 3. Of the 558 horses $(60 \%)$ that received medical intervention, 141 (25\%) had no definitive diagnosis, while 218 horses (39\%) had impactions which affected the large colon $(32 \%)$, small colon $(3 \%)$, stomach $(2 \%)$, caecum $(1 \%)$ and small intestine $(1 \%)$. A displacement of the large colon was diagnosed in 36 horses (6\%), of which 22 horses had a left dorsal displacement of the colon.

\section{Surgical treatment}

The gastrointestinal lesions following exploratory laparotomy are presented in Figs 4 and 5. An exploratory laparotomy was performed on 331 horses (35\%). Lesions were categorised as non-strangulating lesions without mucosal damage $(n=76,22 \%)$, non-strangulating lesions with mucosal damage $(n=102,31 \%)$, non-resected strangulating lesion $(n=$ $134,40 \%)$ and resected strangulating lesions $(n=11,4 \%)$. In 7 horses $(2 \%)$ of the 331 surgical cases no lesion was found, while no diagnosis was recorded for 1 horse. Of all the horses treated surgically, 10 horses underwent more than 1 exploratory laparotomy; 3 were euthanased during the exploratory laparotomy, 2 euthanased in the immediate post-operative period and 5 horses survived to discharge.

Impactions were reported in 75 horses (22\%) and affected the large colon (13\%), small colon $(4 \%)$, small intestine $(4 \%)$,

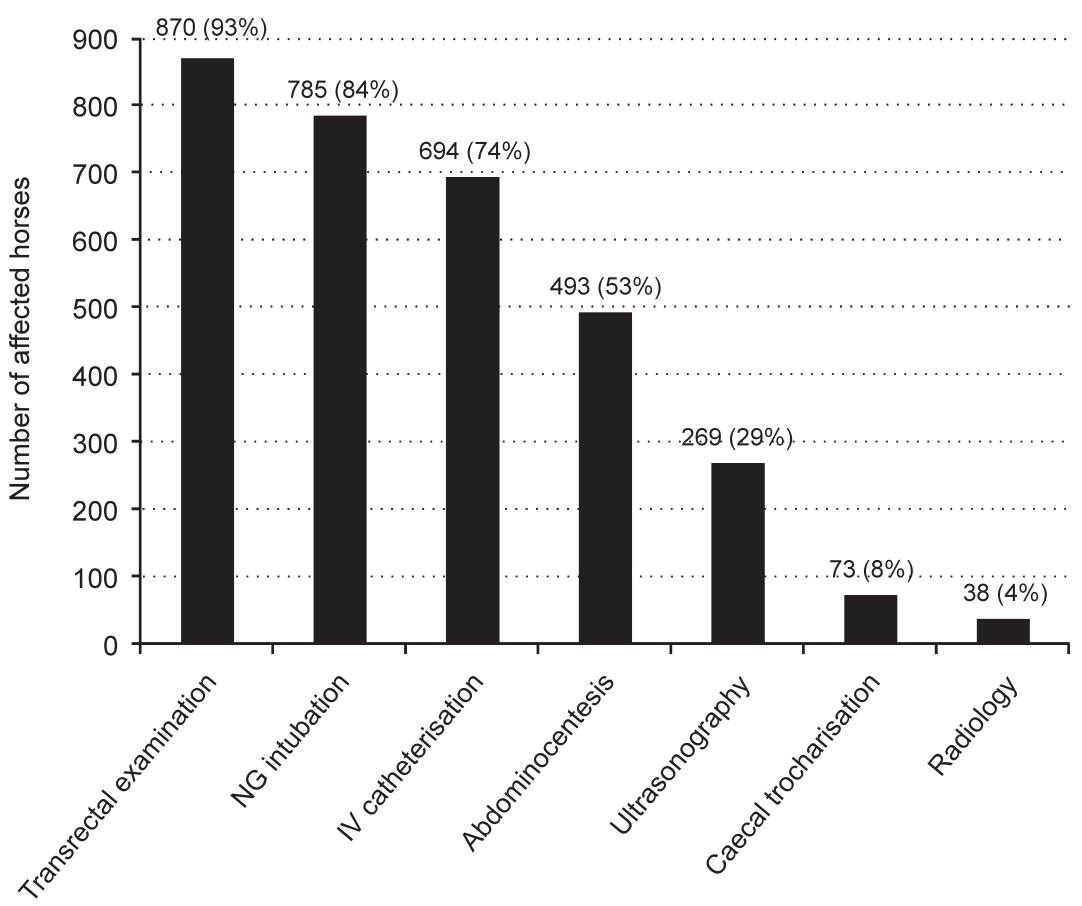

Procedure

Fig. 1: The most-common procedures performed on horses with colic admitted to the Equine Clinic of the OVAH (1998-2007). NG = nasogastric, IV = intravenous. caecum $(1 \%)$ and stomach $(<1 \%)$. Left dorsal displacement of the large intestine was recorded in 36 horses (11\%). Strangulating lipoma occurred in 2 horses but lesions were not corrected by intestinal resection. Strangulating intestinal lesions that were corrected by intestinal resection were recorded in 11 horses. Strangulation of the small intestines occurred in 8 horses and intramural obstruction in 3 horses. Of the 11 horses, 4 survived to discharge, 2 died and 5 were euthanased.

\section{Gastrointestinal causes of colic}

The ten most-common gastrointestinal causes of colic in horses admitted to the OVAH are depicted in Fig. 6. Impaction of the large colon was recorded in $25 \%$ (medical $n=180$, surgical $n=44$ ); displacement of the large colon $15 \%$ (medical $n=36$, surgical $n=97$ ); small intestinal strangulation $7 \%$ (medical $n=0$, surgical $n=58)$; tympany $5 \%$ (medical $n=41$, surgical $n=2$ ); enteritis $4 \%$ (medical $n=31$, surgical $n=8$ ); large

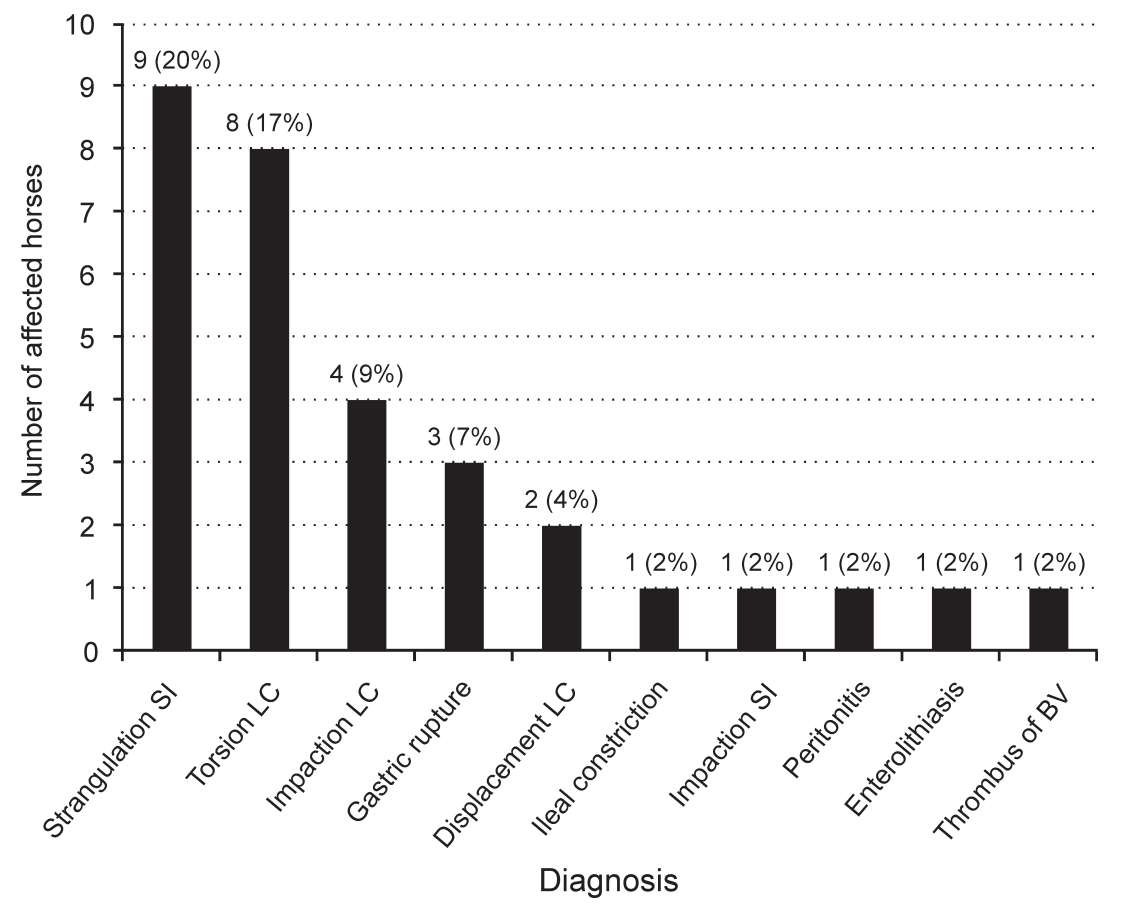

Fig. 2: The diagnosis confirmed at necropsy on 31 of 46 horses which were euthanased or died before treatment at the Equine Clinic of the OVAH (1998-2007). SI = small intestine, $\mathrm{LC}=$ large colon, $\mathrm{BV}=$ blood vessel. 
intestinal torsion $4 \%$ (medical $n=0$, surgical $n=38$ ); colitis $3 \%$ (medical $n=28$, surgical $n=0$ ); small colon impaction $3 \%$ (medical $n=13$, surgical $n=11) ;$ small intestinal impaction $2 \%$ (medical $n=8$, surgical $n=14$ ); and ileus $2 \%$ (medical $n=15$, surgical $n=4$ ).

\section{Survival to discharge}

Of the 935 horses in this report, 737 (79\%) were discharged, $174(18 \%)$ euthanased and $24(3 \%)$ died. Forty horses $(4 \%)$ were euthanased and $6(0.6 \%)$ died before treatment. Of the 558 horses that received medical intervention, $37(6.6 \%)$ were euthanased and $3(0.5 \%)$ died during treatment. Of the 331 horses that received surgical intervention, $64(19 \%)$ were euthanased and $4(1.2 \%)$ died during exploratory laparotomy, while 32 $(9.7 \%)$ were euthanased and $11(3.3 \%)$ died following exploratory laparotomy. The overall survival rate was $93 \%$ and $67 \%$ for horses that received medical and surgical intervention, respectively. Nine horses were euthanased for reasons other than complications due to colic which included fractures, pneumonia, and systemic mycosis. A necropsy was performed on $138(70 \%)$ of the 198 cases that were euthanased or that died.

The median duration of hospitalisation for all horses was 4 days ( 1 to 42 days) while for horses treated medically or surgically it was 4 and 7 days, respectively. On average the median cost per day for the 935 cases included in this report was ZAR 716.41 (R0-13 026.86). The median cost per day for horses treated medically was ZAR 421.14 (R0-5597.82) and for those treated surgically was ZAR 1627.32 (R615-19 307.65).

\section{DISCUSSION}

The aim of assessing a horse with colic is to determine the severity of the colic and to select the appropriate type of medical or surgical intervention. The knowledge of common causes and plausible outcomes of colic events may aid veterinarians when considering appropriate diagnostic methods, therapeutic options and in determining the prognosis for the individual horse. Although studies conducted in other countries dealt with the causes of gastrointestinal colic, this information may not be relevant to horses with colic in South Africa due to geographical differences. To the authors' knowledge this is the 1st study in South Africa to establish causes and outcomes of horses with gastrointestinal colic at a referral hospital.

In the present study the incidence of all colic cases showed no seasonal trends which is in contrast with other stud-

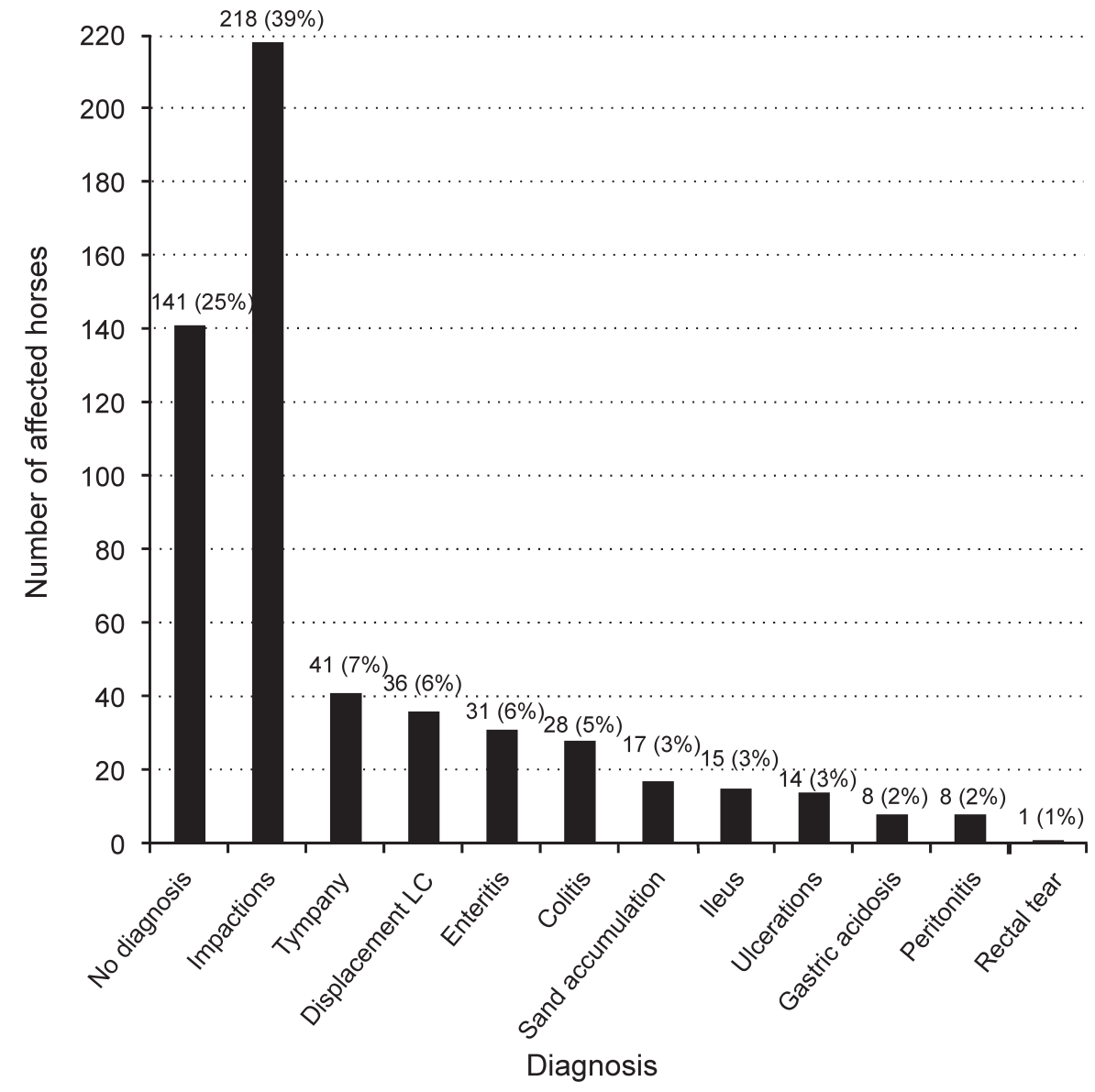

Fig. 3: Specific causes of colic in horses that received medical intervention at the Equine Clinic of the OVAH (1998-2007) $(n=558)$. LC = large colon.

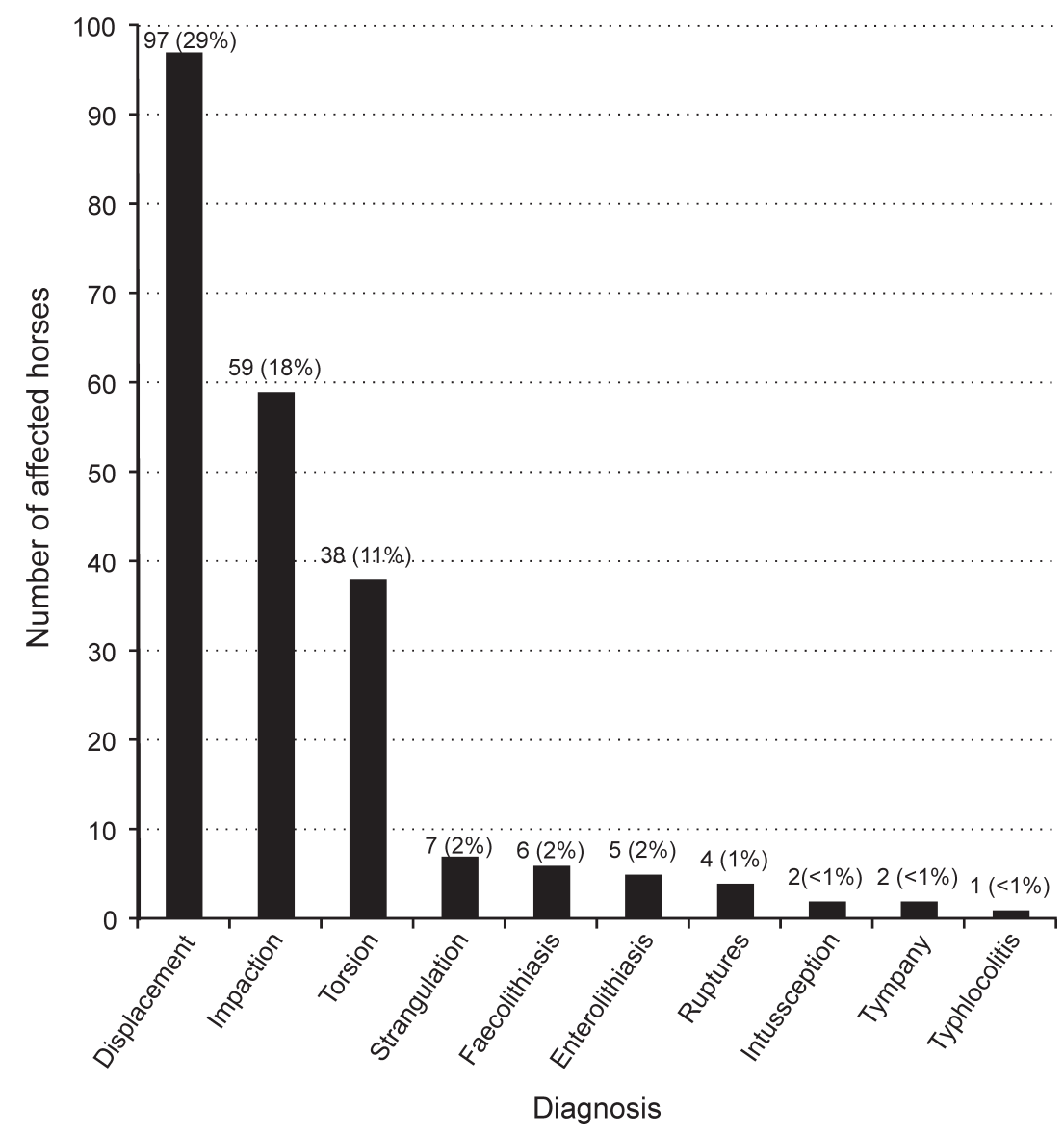

Fig. 4: Specific causes of colic affecting the large intestine in horses that received surgical intervention at the Equine Clinic of the OVAH (1998-2007) (percentage of $n=331$ ). 
ies $^{3,12,18}$. In a study involving Swedish horses admitted for gastrointestinal colic, a larger proportion of all colic cases were seen in the winter months ${ }^{12}$. Studies performed at a United Kingdom-based referral hospital ${ }^{3}$ and at a Thoroughbred training premises in the British Isles ${ }^{18}$ indicated an apparent peak in horses with colic during spring and autumn. The sex distribution of horses in the present study was not evenly divided between females $(43 \%)$ and males (57 \%) and agrees with similar studies ${ }^{1,27}$, while the median age distribution was in contrast to that reported in other studies ${ }^{1,12}$.

At the OVAH equine hospital, equine veterinarians and veterinary students are encouraged to employ the history, physical examination results and clinicopathological data when assessing a horse with colic. The usefulness of various clinical signs and clinical pathology to determine of the appropriate management of horses with colic has been previously reported ${ }^{13,21,26,31,37,41}$. Reports have indicated that heart rate ${ }^{21,31,41}$, mucous membrane colour $^{21}$, capillary refill time ${ }^{37}$, packed cell volume $^{21,31,37}$ and level of pain ${ }^{31,37,41}$ are important predictors of outcome in horses that are hospitalised for colic. However, another study reported that white cell count, packed cell volume, blood $\mathrm{pH}$ and colour of the mucous membranes did not show any prognostic significance ${ }^{41}$. Furthermore, abdominal fluid analysis cannot be used alone to accurately predict lesion type or outcome for horses with colic $^{13}$, but it may contribute to the decision to proceed to surgery ${ }^{26}$.

In the present study clinical examination data, packed cell volume and total serum protein concentration were recorded in $>75 \%$ of admissions and frequently used to assess horses. Diagnostic procedures performed such as rectal examination (93\%), nasogastric intubation $(84 \%)$ and abdominocentesis (53\%) were commonly used to compliment a physical examination.

While the causes of colic in the present study were numerous and in some cases life-threatening, $55 \%$ of all admissions responded to medical intervention and were subsequently discharged. In this study, $32 \%$ of horses referred for medical intervention had large colon impactions while $7 \%$ were suspected to have tympany, which was consistent with results reported in other studies ${ }^{1,29}$. A diagnosis could not be made in $25 \%$ of horses that had medical intervention. It is not uncommon not to determine the cause of colic, as seen in a Canadian study where a diagnosis could not be made in $13 \%$ of horses receiving medical intervention $^{1}$ and $10 \%$ of horses in a

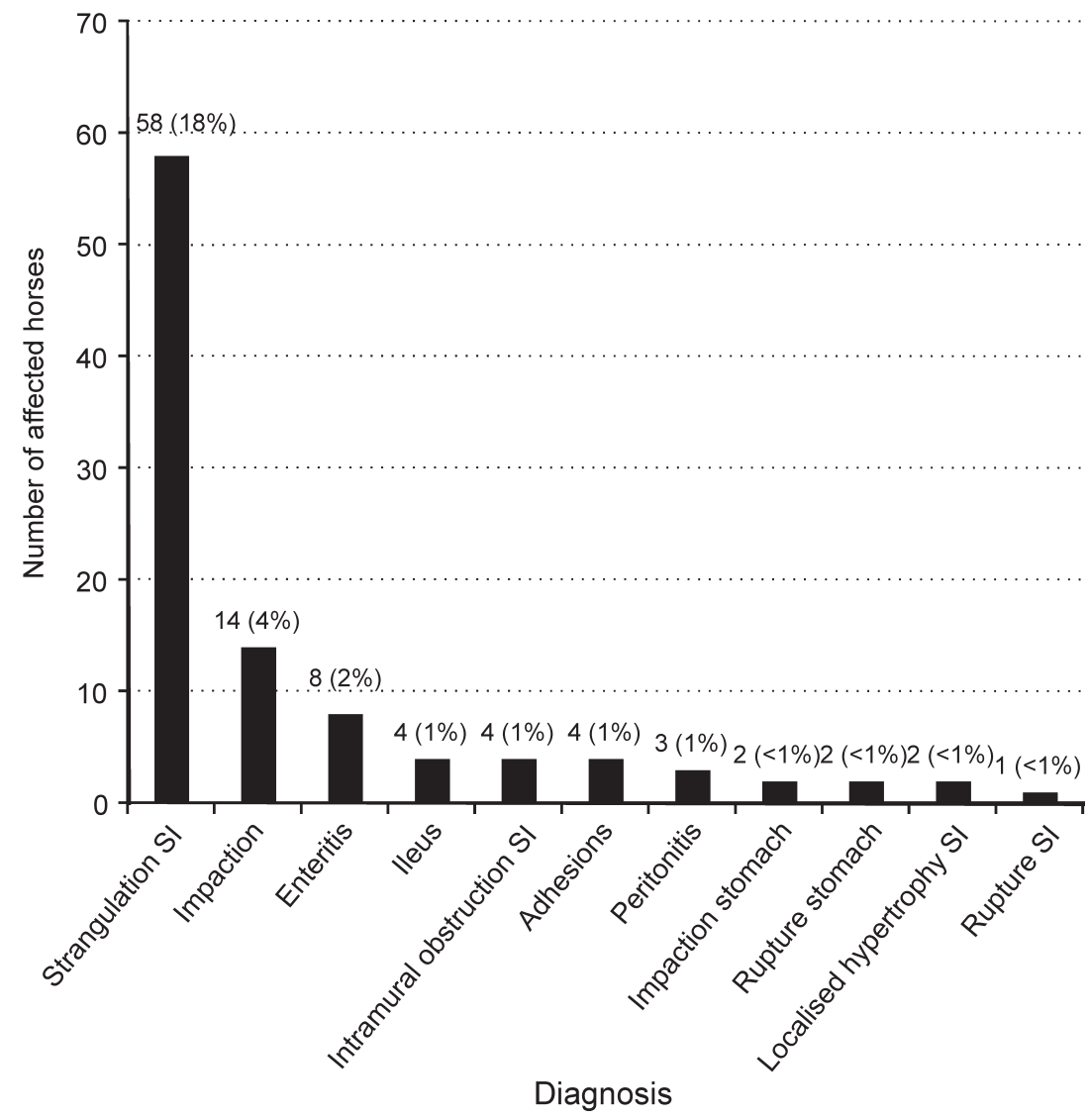

Fig. 5: Specific causes of colic affecting the stomach, small intestine and peritoneum in horses that received surgical intervention at the Equine Clinic of the OVAH (1998-2007) (percentage of $n=331$ ). $\mathrm{SI}=$ small intestine.

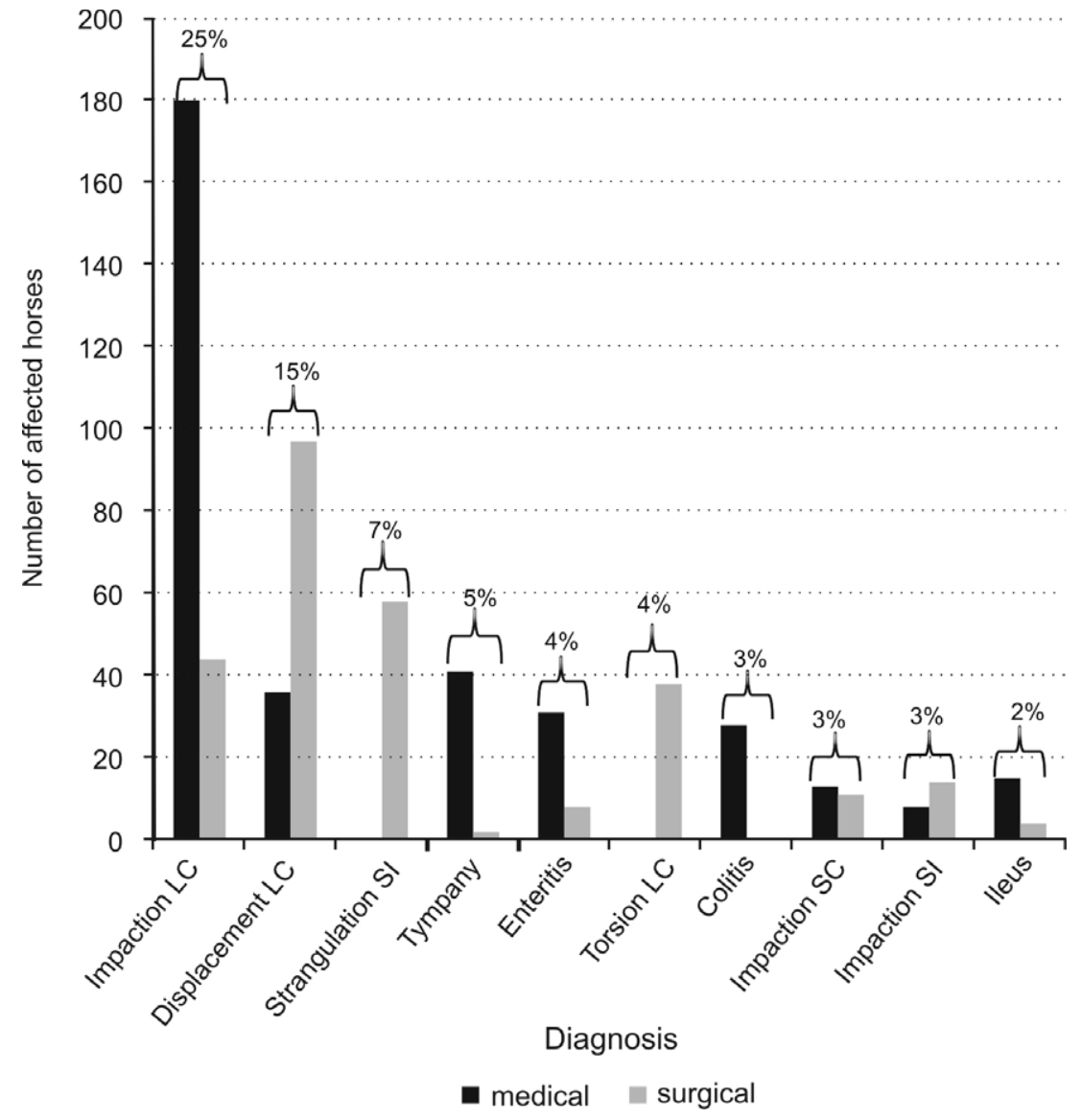

Fig. 6: The 10 most common causes of gastrointestinal colic at the Equine Clinic of the OVAH (1998-2007) ( $n=889$, excludes the pre-treatment euthanasia/death cases). LC = large colon, $\mathrm{SI}=$ small intestine, $\mathrm{SC}=$ small colon . 
study in Georgia, USA ${ }^{27}$.

From the results it is apparent that most horses that had surgical intervention suffered a displacement of the large colon (29\%), while intestinal impactions (22\%), small intestinal strangulation $(18 \%)$ and large intestinal torsion (11\%) occurred less often. Similar findings were reported in a Canadian study where surgical intervention was performed on horses with displacements $(24.5 \%)$ and torsion $(14.3 \%)$ of the large colon ${ }^{1}$. In the present study strangulating lipoma occurred in $<1 \%$ of all admissions, which is in contrast to studies reporting an incidence of $12.5 \%{ }^{1}$ and $10 \%{ }^{15}$. Moreover, several studies have reported that a strangulating lipoma should be an important consideration when examining an aged horse with suspected small intestinal disease $^{1,5,11,15}$. The finding in this study that $2 \%$ of all the colic admissions had caecal impactions is in contrast to a reported incidence of $4.1 \%$ in another study ${ }^{30}$. Horses with enterolithiasis accounted for $<1 \%$ in the present study, which is similar to a study that reported an incidence of $1.7 \%{ }^{8}$, but is in contrast to another study that reported an incidence of $15.1 \%{ }^{16}$. These studies further concluded that breed and diet influence the risk of enterolithiasis, which explains the discrepancies in study results ${ }^{8,16}$.

The common causes of gastrointestinal colic in horses in this study were consistent with results found in several studies in other countries ${ }^{1,12,27,28}$. A Canadian study reported that the 9 most common causes of colic were large colon impactions, large colon displacements, spasmodic colic, large colon volvulus, lipoma, strangulating small intestinal lesions, enteritis, peritonitis and verminous arteritis ${ }^{1}$. A study of 3100 Swedish horses with colic reported that impaction occurs most frequently, followed by torsion/volvulus, enteritis, sand impaction and incarceration of the small intestines ${ }^{12}$. In 2 studies at the University of Georgia, USA, involving 229 and 449 horses, the most common colic causes were large colon displacement and volvulus, large colon impaction and small intestinal obstruction ${ }^{27,28}$.

Compared with this study, a similar pattern of short-term survival was reported in other studies ${ }^{1,10,21,24,41}$. In a report of the outcome of horses with colic admitted to the Liverpool University Equine Hospital, UK, over 12 months, $76 \%$ to $88 \%$ survived the colic surgery ${ }^{10}$, while the survival for horses undergoing surgical intervention for colic at the Bell Equine Veterinary Clinic had a short-term survival rate to discharge of $70.3 \%$ for all horses and $83.15 \%$ for those recovering from anaesthesia $^{24}$. In a Canadian report, a sur- vival rate of $93.6 \%$ for medically treated horses and $73.5 \%$ for surgically treated horses was reported ${ }^{1}$, while in a report of horses with colic in Oslo, Norway, the total survival rate was $63 \%$ with a survival rate of $78 \%$ and $48 \%$ for the medically and surgically treated horses, respectively ${ }^{21}$. In the present study, 10 horses (3\%) needed a 2 nd exploratory laparotomy of which $50 \%$ was discharged, which is consistent with results from a similar study $^{25}$.

This study had several limitations. Although the equine hospital at the OVAH serves a wide geographical region, the results of this study may be biased towards causes of colic that occur more frequently within the OVAH region. Horses admitted may be more likely to have suffered more severe causes of gastrointestinal colic. Owing to the retrospective nature of this study, unavailable records and missing data made accurate interpretation difficult.

In conclusion, most horses in this study were Thoroughbreds (54\%), male (57 \%) and with a mean age of 8.2 years. Clinical examination, transrectal palpation, nasogastric intubation, packed cell volume and total serum protein determination was most commonly performed following admission. The most common causes of horses receiving medical intervention were impactions (39\%), tympany $(7 \%)$ and displacement of the large colon (6\%) while displacement $(29 \%)$, impaction $(22 \%)$ and small intestinal strangulating lesions $(18 \%)$ occurred most often in horses receiving surgical intervention. Overall, impaction and displacement of the large colon was the leading cause of colic in the population of horses. Fifty-five per cent of all the admissions responded favourably to medical intervention, while the recovery rate for horses receiving both medical and surgical intervention was comparable with those of other studies.

\section{ACKNOWLEDGEMENTS}

The authors acknowledge the dedication and support of the students and staff of the Equine Clinic. The retrieval of the archived records was performed by Mrs. Lotter and Mrs Pansegrouw. A portion of this work was presented as an abstract at the 15th Società Italiana Veterinari per Equini Congress, Società Federata, Bologna, Italy, 23-25 January 2009.

\section{REFERENCES}

1. Abutarbush S M, Carmalt J L, Shoemaker R W 2005 Causes of gastrointestinal colic in horses in western Canada: 604 cases (1992 to 2002). Canadian Veterinary Journal 46: 800-805

2. Abutarbush S M, Naylor J M 2005 Comparison of surgical versus medical treatment of nephrosplenic entrapment of the large colon in horses: 19 cases (1992-2002). Journal of the American Veterinary Medical Association 227: 603-605

3. Archer D C, Pinchbeck G L, Proudman C J, Clough H E 2006 Is equine colic seasonal? Novel application of a model based approach. BMC Veterinary Research 2: 27-37

4. Archer D C, Proudman C J 2006 Epidemiological clues to preventing colic. Veterinary Journal 172: 29-39

5. Brosnahan M M, Paradis M R 2003 Demographic and clinical characteristics of geriatric horses: 467 cases (1989-1999). Journal of the American Veterinary Medical Association 223: 93-98

6. Chaffin M K, Carmen Fuenteabla I, Schumacher J, Welch R D, Edwards J F 1992 Idiopathic muscular hypertrophy of the equine small intestine: 11 cases (1980-1991). Equine Veterinary Journal 24: 372-378

7. Cohen N D 2003 The John Hickman memorial lecture: colic by numbers. Equine Veterinary Journal 35: 343-349

8. Cohen N D, Vontur C A, Rakestraw P C 2000 Risk factors for enterolithiasis among horses in Texas. Journal of the American Veterinary Medical Association 216: 1787-1794

9. Dabareiner R M, White N A 1995 Large colon impaction in horses: 147 cases (19851991). Journal of the American Veterinary Medical Association 206: 679-685

10. DEFRA 2006 Equine disease surveillance Liverpool university equine hospital colic data. Online at: www.defra.gov.uk/ animalh/disease/vetsurveillance/species/ horses/index.htm (accessed 1 October 2008)

11. Edwards G B, Proudman C J 1994 An analysis of 75 cases of intestinal obstruction caused by pedunculated lipomas. Equine Veterinary Journal 26: 18-21

12. Egenvall A, Penell J, Bonnett B N, Blix J, Pringle J 2008 Demographics and costs of colic in Swedish horses. Journal of Veterinary Internal Medicine 22: 1029-1037

13. Freden G O, Provost P J, Rand W M 1998 Reliability of using results of abdominal fluid analysis to determine treatment and predict lesion type and outcome for horses with colic: 218 cases (1991-1994). Journal of the American Veterinary Medical Association 213: 1012-1015

14. Freeman D E, Schaeffer D 2005 Short-term survival after surgery for epiploic foramen entrapment compared with other strangulating diseases of the small intestine in horses. Equine Veterinary Journal 37: 292-295

15. Garcia-Seco E, Wilson D A, Kramer J, Keegan K G, Branson K R, Johnson P J, Tyler J W 2005 Prevalence and risk factors associated with outcome of surgical removal of pedunculated lipomas in horses: 102 cases (1987-2002). Journal of the American Veterinary Medical Association 226: 1529-1537

16. Hassel D M, Langer D L, Snyder J R, Drake C M, Goodell M L, Wyle A 1999 Evaluation of enterolithiasis in equids: 900 cases (19731996). Journal of the American Veterinary Medical Association 214: 233-237

17. Henderson I S F, Mair T S, Keen J A, Shaw D J, McGorum B C 2008 Study of the shortand long-term outcomes of 65 horses with peritonitis. The Veterinary Record 163: 293297

18. Hillyer M H, Taylor F G R, French N P 2001 A cross-sectional study of colic in horses on Thoroughbred training premises in the British Isles in 1997. Equine Veterinary Journal 33: 380-385 
19. Hughes K J, Dowling B A, Matthews S A, Dart A J 2003 Results of surgical treatment of colic in miniature breed horses: 11 cases. Australian Veterinary Journal 81: 260-264

20. Husted L, Andersen M S, Borggaard O K, Houe H, Olsen S N 2005 Risk factors for faecal sand excretion in Icelandic horses. Equine Veterinary Journal 37: 351-355

21. Ihler C F, Larsen Venger J, Skjerve E 2004 Evaluation of clinical and laboratory variables as prognostic indicators in hospitalised gastrointestinal colic horses. Acta Veterinaria Scandinavica 45: 109-118

22. Kaneene J B, Miller R, Ross W A, Gallagher K, Marteniuk J, Rook J 1997 Risk factors for colic in the Michigan (USA) equine population. Preventative Veterinary Medicine 30: $23-36$

23. Mair T S, Hillyer M H, Taylor F G R 1990 Peritonitis in adult horses: a review of 21 cases. Veterinary Record 126: 567-570

24. Mair T S, Smith L J 2005 Survival and complication rates in 300 horses undergoing surgical treatment of colic. Part 1: Shortterm survival following a single laparotomy. Equine Veterinary Journal 37: 296-302

25. Mair T S, Smith L J 2005 Survival and complication rates in 300 horses undergoing surgical treatment of colic. Part 4: Early (acute) relaparotomy. Equine Veterinary Journal 37: 315-318

26. Matthews S, Dart A J, Reid S W J, Dowling B A, Hodgson D R 2002 Predictive values, sensitivity and specificity of abdominal fluid variables in determining the need for surgery in horses with an acute abdominal crisis. Australian Veterinary Journal 80: 132-136

27. Morris DD, Crowe N, Johnson K, Moore J N
1992 Association of signalment and management factors with causes for colic in horses. Proceedings of the 38th Annual Convention of the American Association of Equine Practitioners, Orlando, Florida, 30 November-2 December 1992: 441

28. Morris D D, Moore J N, Ward S 1989 Comparison of age, sex, breed, history and management in 229 horses with colic. Equine Veterinary Journal Supplement 7: 129-132

29. Penell J C, Egenvall A, Bonnett B N, Olson P, Pringle J 2005 Specific causes of morbidity among Swedish horses insured for veterinary care between 1997 and 2000. Veterinary Record 157: 470-477

30. Plummer A E, Rakestraw P C, Hardy J, Lee R M 2007 Outcome of medical and surgical treatment of cecal impaction in horses: 114 cases (1994-2004). Journal of the American Veterinary Medical Association 231: 1378-1385

31. Proudman C J, Dugdale A H A, Senior J M, Edwards G B, Smith J E, Leuwer M L, French N P 2006 Pre-operative and anaesthesia-related risk factors for mortality in equine colic cases. Veterinary Journal 171: 89-97

32. Ragle C A, Meagher D M, Lacroix C A, Honnas C M 1989 Surgical treatment of sand colic results in 40 horses. Veterinary Surgery 18: 48-51

33. Ragle C A, Snyder J R, Meagher D M, Honnas C M 1992 Surgical treatment of colic in American miniature horses: 15 cases (1980-1987). Journal of the American Veterinary Medical Association 201: 329-331

34. Rothenbuhler R, Hawkins J F, Adams S B, Lescun T B, Weil A B, Glickman L T, Fessler J F, Glickman N G 2006 Evaluation of surgi- cal treatment for signs of acute abdominal pain in draft horses: 72 cases (1983-2002). Journal of the American Veterinary Medical Association 228: 1546-1550

35. Ruggles A J, Ross M W 1991 Medical and surgical management of small-colon impaction in horses: 28 cases (1984-1989). Journal of the American Veterinary Medical Association 199: 1762-1766

36. Smith B P, Magdesian K G 2002 Alterations in alimentary and hepatic function. In Smith B P (ed.) Large animal internal medicine (3rd edn). Mosby, St Louis: 102-122

37. Thoefner M B, Ersbøll A K, Hesselholt M 2000 Prognostic indicators in a Danish hospital-based population of colic horses. Equine Veterinary Journal Supplement 32: 11-18

38. Tinker M K, White N A, Lessard P, Thatcher C D, Pelzer K D, Davis B, Carmel D K 1997 Prospective study of equine colic incidence and mortality. Equine Veterinary Journal 29: 448-453

39. Tinker M K, White N A, Lessard P, Thatcher C D, Pelzer K D, Davis B, Carmel D K 1997 Prospective study of equine colic risk factors. Equine Veterinary Journal 29: 454-458

40. Traub-Dargatz J L, Kopral C A, Hillberg Seitzinger A, Garber L P, Forde K, White N A 2001 Estimate of the national incidence of and operation-level risk factors for colic among horses in the United States, spring 1998 to spring 1999. Journal of the American Veterinary Medical Association 219: 67-71

41. Van der Linden M A, Laffont C M, Sloet van Oldruitenborgh-Oosterbaan M M 2003 Prognosis in equine medical and surgical colic. Journal of Veterinary Internal Medicine 17: $343-348$ 